\title{
Exploring gender differences in the Italian traditional pizza consumption
}

\author{
Gioacchino Pappalardo ${ }^{a *}$, Giuseppe Di Vita ${ }^{a}$, Giovanni La Via ${ }^{a}$, Severino Romano ${ }^{b}$, Antonella \\ Vastola $^{\mathrm{b}}$, Mario Cozzi ${ }^{\mathrm{b}}$, Mario D'Amico ${ }^{\mathrm{a}}$ \\ a University of Catania, Italy \\ b Univesity of Basilicata, Italy
}

\section{Summary}

The studies on gender differences in food consumption have experienced a deep and remarkable development from several perspectives. Many studies have been addressed to highlight whether differences exist among males and females in purchasing behaviors or consumption for specific food products but no study pizza consumption segmented by gender has been carried out. This study evaluates gender differences in the consumption of traditional Italian pizza. For this purpose, a quantitative study was conducted on a representative sample of Sicilian pizza consumers. Our findings showed that there exist any gender differences in pizza consumption that appear to be strongly related to preferences for sensory attributes such as "smell", "appearance", "crunchiness" as well for "price". Our findings show that gender differences can significantly influence the buying process of this traditional Italian food, and they have important implications for the food industry since gender differences should be taken into account in new formulation and characterization of pizza.

Key words: pizza, gender differences, qualitative attributes preferences.

Jel codes: D12

Type: Article - Submitted: 13/06/2018 - Accepted: 04/12/2018

* Corresponding author: Gioacchino Pappalardo, Assistant professor in Agricultural Economics. Department of Agriculture, Food and Environment (Di3A), University of Catania (Italy). E-mail: gioacchino.pappalardo@unict.it, gvitae@hotmail.com, giovanni.lavia@unict.it, severino.romano@unibas.it, antonella.vastola@unibas.it,mario.cozzi@unibas.it,mario.damico@unict.it 


\section{Introduction}

The studies on gender differences in food consumption have experienced a deep and remarkable development from several perspectives. A strand of literature explored gender behavior linked to social and psychological issues, observing difference in "charitable giving, bargaining, and household decision making" (Andreoni \& Vesterlund, 2001) as well as in generosity (Cox \& Deck, 2006), in impulse purchase (Dittmar et al., 1995) and in social preferences (Croson \& Gneezy, 2009).

Concerning agro-food sector, several studies have been addressed to highlight whether differences exist among males and females in purchasing behaviors or consumption for specific food products (Allegra et al., 2012; Lanfranchi et al., 2017) and even for locally produced food (Girgenti et al., 2016; Bazzani et al., 2017; Giampietri et al., 2018). Differences between males and females in researches that related gender to food were found by Rappoport et al. (1993). Several later studies on gender differences argued that females have been frequently reported to engage in far more health-promoting behaviors than males and to obtain healthier lifestyle patterns (Arganini et al., 2012). Regarding eating habits, many studies indicate that females are more aware about diet and health-diet relationship implications and also embrace suggested dietary changes to a greater degree than males (Barker et al., 1995; Courtenay, 2000; Friel et al., 1999; Girois et al., 2001; Thiele \& Weiss, 2003). Fagerli \& Wandel (1999) discovered that females possess greater knowledge than males of the effects of food on health.

Studies conducted in modern western societies report consistent associations between gender and specific foods, where meat (especially red meat), alcohol, and big portion sizes are associated with masculinity, while vegetables, fruit, fish and sour dairy products are associated with femininity (Arganini et al., 2012; Lassen et al., 2016). In a Pan-EU survey of 14331 subjects, female respondents perceived that "quality/freshness", "price", "trying to eat healthy" and "family preferences" were the most important influences affecting food choice, whereas "taste" was the most frequently selected factor affecting food choice of male respondents (Lennenäs et al., 1997). In a different study, females have been reported to be more likely than males to mention more vegetables or less fat or balance as a part of a healthy diet (Margetts et al., 1997).

One possible mechanism for the gender-specific patterns of healthy food choices might be related to nutritional knowledge. Several studies have reported gender differences in the knowledge nutritional information (Crawford \& Baghurst, 1990; Tate \& Cade, 1990; Parmenter et al., 2000; Kiefer et al., 2005; Prattala et al., 2006), supporting the hypothesis that differences in awareness could contribute to gender differences in intake (Arganini et al., 2012). There is a consistent body of literature (Wardle et al., 2000; Liebman et al., 2001; Wardle \& Griffith, 2001; Afifi-Soweid et al., 2002; Kostanski et al., 2004; Johnson 
\& Wardle, 2005) that clearly indicates that there are important gender differences in weight concern and body self-perception. Weight control/body perception are known to influence food choice decisions, mainly in females (Glanz et al., 1998; Goode et al., 1995; Rozin et al., 1999).

Females seem to have more positive attitudes towards local foods than males. Therefore, females may be more willing to purchase and pay for local foods (Gracia et al, 2012). Gender is one of the most relevant factor that affects consumption of organic products (Gil et al., 2000; Rimal et al., 2005; Napolitano et al., 2010; D'Amico et al., 2016) and the main reason for organic food consumption in females is eating a healthy diet, in males it is a social function and to a lesser degree, comes from respect for the environment (Olivas et al., 2012). Moreover, males and females were found to attach different degrees of importance to some attributes related to purchasing decisions on fresh fruit and vegetables. Akpinar et al., (2009) found statistically significant relationship between gender and fresh fruit and vegetables attributes like taste, smell, display and the shopping environment.

Despite several studies have been conducted on gender differences in food consumption, characterizing factors that determine gender differences as well as new methods for constructing a survey instrument and organizing data analysis, remains an unresolved issue and it appears still relevant to better understand differences between males and females in food consumption. The consumption of pizza is currently spread in all over the world but in its original Italian formulation, pizza it is commonly made with tomato, sliced mozzarella, salt, extra-virgin olive oil, wheat flour type "0", brewer's yeast, and drinkable natural water, and it consists of flatbread topped baked in an oven with tomato sauce and mozzarella. Pizza, in its traditional Italian recipe, represents one of the most important street food as well as restaurant food and it is widespread in all socio-economic classes of Italian community. So far, few studies have analyzed how qualitative attributes affect the consumption of pizza (Di Vita et al., 2016a). A recent study observed the qualitative profile of pizza, as perceived by the Italian consumer, and it highlighted the preference of consumers for buying fresh and hand-crafted pizza, preferably prepared with organic ingredients and with a normal calories content (Di Vita et al., 2016b).

As a consequence, to the knowledge of authors, no study on gender differences of the attributes that affect the consumption of pizza has been carried out. However, knowing how gender differences can affect the consumption of pizza could have important implication for actors involved in pizza sector since the adoption of marketing strategies explicitly related to the consumer gender can increase consumers' demand for pizza. For this purpose, in this paper we aim to explore factors affecting gender differences in the consumption of pizza by interviewing a sample of consumers in Sicily (Italy) during the second semester of 2016. 


\section{Procedure}

A quantitative study was conducted in the city of Catania located in the Italian region of Sicily in 2016. With the purpose of assessing gender differences related to attributes for traditional Italian pizza's consumption, a structured questionnaire was administered through face to face interviews to a sample of 202 regular consumers of pizza which were randomly selected to achieve balanced socio-demographic characteristics. We considered "regular consumers" those who buy pizza at least three times a month. A specific questionnaire containing closed-ended questions was designed. The questionnaire was organized into three main sections. The first section asked about the main food habits of consumers with respect to motivation, consumption frequency, eating behavior and place of purchase of pizza. The second part focused on sensory aspects, extrinsic attributes and healthy characteristics of pizza. The final part of the questionnaire collected data on the social and economic characteristics of the interviewees. Data were collected as follows: $60 \%$ of the sample were interviewed at large retail stores, while the remaining $40 \%$ were interviewed at pizzeria restaurant.

To identify the relative importance given by consumers to qualitative attributes of pizza, respondents were presented with a list of 13 qualitative attributes of pizza (Table 1).

Table 1. Qualitative attributes and other explanatory variables employed in the analysis

\begin{tabular}{|l|l|c|}
\hline \multicolumn{1}{|c|}{ Variable } & \multicolumn{1}{c|}{ Description } & Type (1) \\
\hline Taste & Extent to which consumption of pizza is appealing to the senses & Cat \\
\hline Smell & Extent to which pizza smells like & Cat \\
\hline Colour & The quality of pizza of producing different sensations on the eye & Cat \\
\hline Package & How pizza is packed and wrapped or boxed & Cat \\
\hline Crunchiness & Extent to which pizza is crunchy & Cat \\
\hline Softness & Extent to which pizza is easy to cut, compress, or fold & Cat \\
\hline Sapidity & Extent to which pizza has a strong pleasant flavor & Cat \\
\hline Italian Flour & The use of Italian flour for making pizza & Cat \\
\hline Price & The price that is paid for pizza & Cat \\
\hline Low environmental impact & Effect of pizza production on the environment & Cat \\
\hline Local raw materials & The use of local raw materials for making pizza & Continuous \\
\hline Food safety & Extent to which consumption of pizza will not cause illness & Dummy \\
\hline Nutritional content & Extent to which consumption of pizza is nutrient & Cat \\
\hline Age & $18-70$ & Cat \\
\hline Gender & 1 if female, 0 if male & $\begin{array}{l}\text { (= None } \\
\text { Education }\end{array}$ \\
\hline Incomentary & $\begin{array}{l}2=\text { Medium } \\
\text { 4= Diploma }\end{array}$ & $\begin{array}{l}\text { 1 less than } € 1,000 \\
2 \text { from } € 1,001 \text { to } € 1,500\end{array}$ \\
\hline
\end{tabular}




\begin{tabular}{|l|l|c|}
\hline Variable & Description & Type (1) \\
\hline & 3 from $€ 1,501$ to $€ 2,000$ & \\
& 4 from $€ 2,001$ to $€ 3,000$ \\
& 6 from $€ 3,001$ to $€ 4,000$ \\
& 7 more than $€ 5,000$ \\
& & \\
\hline
\end{tabular}

These attributes were identified through preliminary focus groups held at traditional pizza restaurants, and a group of selected consumers was invited to express their attitudes for Margherita pizza consumption linked to eating habits, shopping places, frequency, as well as to the most important sensory attributes such as colour, wheat typology, price, method of production, and so on. These focus groups allowed to identify broad items in the pizza consumption. In addition, to identify the main attributes of pizza, we have revisited the existing literature on food values associated with food consumption (Gutman, 1992; McCluskey et al, 2005; Lusk and Briggeman, 2009; Lusk, 2011; Adjala et al, 2013; Pappalardo and Lusk, 2016). Participants were asked to rate their opinion for these attributes based on 7-point Likert-type scale, ranging from "not important" to "very important" $(1=$ not important, $7=$ very important).

Initially, coupling gender of respondents and score of the relative importance assigned to the qualitative attributes, we assessed gender differences in consumption of pizza. Specifically, to identify gender differences in consumption of traditional Italian pizza we assessed gender differences for the attributes reported in Table 1. For this purpose, we adapted the procedure adopted by Missagia et al. (2012) calculating mean differences, standard deviations and results of the t-test for each of the 13 qualitative attributes.

Afterwards, for those attributes for which the t-test showed significant differences between males and females, a further analysis was carried out using ordered logit regression models to analyze whether and to what extent the importance given by consumers to the attributes of pizza is influenced by the socio-economic characteristics of the consumer. Specifically, we estimated ordered logit regression models in which the dependent variables were the significant attribute obtained from the t-test analysis and the independent variables concerned socio-economics characteristics of consumer: age, gender, education and income.

\section{Results}

3.1 Descriptive analysis 
Table 2 shows socio-demographic characteristics of the sample. The interviewed sample was composed of females $(57,9 \%)$ and males $(42,1 \%)$; the mean age of sample was included among four classes: $18-30$ years old (54,5\%), 31-45 years old (28,2\%), 46-60 years old (10,9\%), over 60 years old $(6,4 \%)$. The level of education is made up in $23,8 \%$ of cases by a primary education, while $53,5 \%$ of sample have a secondary school education (diploma) and only $22,7 \%$ have a graduate or postgraduate degree. The most common classes of household income were less than 1.5000 euro/month.

Table 2. Summary statistics for socio-demographic variables

\begin{tabular}{lc}
\hline Variable & $\begin{array}{c}\text { Percentage of total } \\
\text { sample (N =202) }\end{array}$ \\
\hline Gender & 57.9 \\
Female & 42.1 \\
Male & \\
Age & 54.5 \\
$18-30$ & 28.2 \\
$31-45$ & 10.9 \\
$46-60$ & 6.4 \\
$>60$ & \\
Level of education & \\
Low level of education (elementary and medium school) & 23.8 \\
Medium level of education (high school) & 53.5 \\
High level of education(degree and others) & 22.7 \\
Family average income & \\
Low income (up to 1,500 euro/month) & \\
Medium income (from 1,501 to 3,000 euro/month) & 22.8 \\
High income (over 3,000 euro/month) & 22,8 \\
Not answer & 9.5 \\
\hline Not our elaborions from sanpled dat & 44.9 \\
\hline
\end{tabular}

Note: our elaborations from sampled data.

To explore the preferences of males and females in terms of importance given to the qualitative attributes of pizza, the values of means, standard deviation, mean differences and significance of the ttest were analyzed for each of the 13 examined qualitative attributes (Table 3). Remembering that interviewed were asked to rate their evaluation on a 7-point Likert-type scale from 1 (not important) to 7 (very important), all means are above the neutral value of 4 highlighting that respondents tend to give high importance to the 13 attributes related to pizza's quality.

For the first examined attribute "taste", the mean difference between genders was not significant (last column of table 3), supporting the idea that males and females consider "taste" similarly in consumption of pizza. This result is due to the high importance assigned to taste as an attribute for consumption of pizza by both genders. 
There were no significant differences between males and females regarding attribute "food safety" although previous studies observed distinct behavior between males and females when dealing with food safety issues (Fagerli \& Wandel, 1999; Miles et al., 2004; Arganini et al., 2012; Lassen et al., 2016). Likely, this result is due to the heightened awareness among consumers on food safety caused by the recent foodborne illness outbreaks as showed by the high importance assigned to this attribute by both genders (high mean value). In the same way, there were not significant differences between males and females for the attribute "nutritional content" despite several studies have demonstrated that females are more concerned about healthy eating habits than males (Kiefer et al., 2005; Prattala et al., 2006). Likely, the absence of gender differences regarding "nutritional content" can be due to the fact that pizza is very popular among consumers making overshadow this attribute.

On the contrary, significant gender differences have been revealed by "price" that is more important for females than males. This result is in line with findings of Gracia et al. (2012) who detected that females have more positive attitudes towards local foods and more willing to purchase and pay for them. In addition, this finding could be explained by different levels of income between males and females and therefore by the importance given by females to the pizza as a cheap food. Others significant gender differences are related to the attributes "smell", "appearance" and "crunchiness". Females assign more importance than males to the aforementioned attributes confirming what already reported in previous studies (Akpinar et al., 2009) who detected gender differences related to these types of attributes. On the contrary, males and females had similar views over other qualitative attributes of pizza like "softness" and "sapidity"; this last result is in line with a previous research carried out on willingness to pay for low-salt bread, whereas consumers' acceptance for salty attribute is not influenced by gender (Di Vita et al., 2016c).

Finally, no statistical differences between males and females have been observed for the other examined attributes such as "local raw materials", "environmental impact" and "packaging". Both females and males judge equally important these qualitative attributes about pizza.

Table 3. Summary statistics for pizza's qualitative attributes

\begin{tabular}{|c|c|c|c|c|c|c|}
\hline \multirow{2}{*}{ Attributes } & \multicolumn{2}{|c|}{ Mean } & \multicolumn{2}{|c|}{ Std. deviation } & \multirow{2}{*}{$\begin{array}{c}\begin{array}{c}\text { Mean } \\
\text { difference }\end{array} \\
(\mathbf{a})-(\mathbf{b})\end{array}$} & \multirow{2}{*}{$\begin{array}{c}\text { Significance } \\
\text { of t-test }\end{array}$} \\
\hline & Female (a) & Male (b) & Female & Male & & \\
\hline Taste & 6.78 & 6.84 & 0.48 & 0.40 & -0.06 & 0.367 \\
\hline Smell & 6.48 & 6.24 & 0.79 & 0.97 & 0.24 & $0.052 *$ \\
\hline Appearance & 6.13 & 5.85 & 1.05 & 1.12 & 0.28 & $0.070 *$ \\
\hline Package & 4.62 & 4.62 & 1.57 & 1.46 & $-0,01$ & 0.970 \\
\hline Crunchiness & 6.03 & 5.61 & 1.39 & 1.70 & 0.41 & $0.059 *$ \\
\hline
\end{tabular}




\begin{tabular}{|c|c|c|c|c|c|c|}
\hline \multirow{2}{*}{ Attributes } & \multicolumn{2}{|c|}{ Mean } & \multicolumn{2}{|c|}{ Std. deviation } & \multirow{2}{*}{$\begin{array}{c}\begin{array}{c}\text { Mean } \\
\text { difference }\end{array} \\
\text { (a)-(b) }\end{array}$} & \multirow{2}{*}{$\begin{array}{l}\text { Significance } \\
\text { of t-test }\end{array}$} \\
\hline & Female (a) & Male (b) & Female & Male & & \\
\hline Softness & 4.94 & 4.69 & 1.94 & 1.93 & 0.25 & 0.373 \\
\hline Sapidity & 5.34 & 5.15 & 1.47 & 1.54 & 0.19 & 0.379 \\
\hline Italian Flour & 5.85 & 5.84 & 1.43 & 1.59 & 0.01 & 0.959 \\
\hline Price & 5.72 & 5.38 & 1.30 & 1.41 & 0.34 & $0.076 *$ \\
\hline Low environmental impact & 5.56 & 5.48 & 1.51 & 1.38 & 0.07 & 0.724 \\
\hline Local raw materials & 6.15 & 6.04 & 1.14 & 1.28 & 0.11 & 0.520 \\
\hline Food safety & 6.66 & 6.62 & 0.72 & 0.71 & 0.03 & 0.735 \\
\hline Nutritional content & 6.05 & 5.87 & 1.24 & 1.20 & 0.18 & 0.301 \\
\hline
\end{tabular}

\subsection{Effects of attributes on gender consumption of pizza}

The descriptive statistics and unconditional tests do not completely reveal the effect of attributes on gender consumption of pizza. To estimate the effects of gender along with other socio-economic characteristics on pizza's attributes, four ordered logit models were estimated. According with the results of t-test as reported in the previous Table 3, the four attributes with a significant statistical difference between females and males were specified as a function of consumer's socio-economic characteristics. Thus, the dependent variables in the four ordered logit regressions were as follow: 1) smell, 2) appearance, 3 ) crunchiness and 4) price. The independent variables in each regression were: age, gender, education and income. The dependent variables are ranked in ascending order and indicates the importance (from 1 to 7 ) that interviewed given to the attributes. The frequencies of the seven categories of the four significant attributes are shown in Table 4. The highest frequencies (6 and 7) for the four attributes were recorded by females.

Table 4. Frequencies of the answer categories for the attributes with significant gender difference

\begin{tabular}{|c|c|c|c|c|c|c|c|c|}
\hline \multirow[b]{2}{*}{ Variable } & \multirow[b]{2}{*}{ Category } & \multicolumn{7}{|c|}{ Frequency } \\
\hline & & 1 & 2 & 3 & 4 & 5 & 6 & 7 \\
\hline \multirow{2}{*}{ Smell } & Males & 0 & 1 & 0 & 4 & 10 & 28 & 42 \\
\hline & Females & 0 & 0 & 1 & 1 & 13 & 28 & 74 \\
\hline \multirow{2}{*}{ Appearance } & Males & 1 & 0 & 1 & 8 & 15 & 34 & 26 \\
\hline & Females & 0 & 1 & 1 & 10 & 12 & 39 & 54 \\
\hline \multirow{2}{*}{ Crunchiness } & Males & 4 & 3 & 4 & 6 & 13 & 19 & 36 \\
\hline & Females & 3 & 1 & 6 & 3 & 10 & 38 & 56 \\
\hline \multirow{2}{*}{ Price } & Males & 1 & 3 & 2 & 17 & 18 & 22 & 22 \\
\hline & Females & 2 & 1 & 4 & 9 & 28 & 34 & 39 \\
\hline
\end{tabular}


By observing the values of the regression coefficients for the examined attributes, as reported in Table 5, it can be possible to argue that "gender" always significantly affects the importance given to the aforementioned attributes. Moreover, conditional analysis provides further insights with respect to the results emerged from unconditional analysis as reported in the previous Table 3. For "smell" and "crunchiness" attributes, "gender" along with "education" affect the probability to obtain a high score of importance. In particular, females with medium or low-level of education increase the probability of "smell" and "crunchiness" being a high score of importance. As for "appearance", females with medium or low-level of income increase the probability that this attribute has a high score. Finally, only "gender" positively affects "price", that is females pay more attention to price of pizza than males regardless other socio-economic characteristics.

Table 5. Ordered logit model results for the significant variables

\begin{tabular}{|c|c|c|c|c|}
\hline Attribute & Variable & Coefficient & p-value & \\
\hline \multirow{5}{*}{ Smell } & Age & 0.016 & 0.182 & \multirow[b]{2}{*}{$* *$} \\
\hline & Gender & 0.578 & 0.049 & \\
\hline & Education & -0.404 & 0.048 & $* *$ \\
\hline & Income & -0.091 & 0.250 & \\
\hline & Chi-square: & 48.607 & & \\
\hline \multirow{5}{*}{ Appearance } & Age & 0.003 & 0.765 & \multirow{3}{*}{$* *$} \\
\hline & Gender & 0.533 & 0.048 & \\
\hline & Education & -0.128 & 0.477 & \\
\hline & Income & -0.124 & 0.085 & $*$ \\
\hline & Chi-square: & 50,772 & & \\
\hline \multirow{5}{*}{ Crunchiness } & Age & 0.002 & 0.827 & \multirow{4}{*}{$\begin{array}{l}* \\
* * *\end{array}$} \\
\hline & Gender & 0.517 & 0.062 & \\
\hline & Education & -0.604 & 0.002 & \\
\hline & Income & 0.0008 & 0.991 & \\
\hline & Chi-square: & 49,432 & & \\
\hline \multirow{5}{*}{ Price } & Age & 0.015 & 0.143 & \multirow{4}{*}{$* *$} \\
\hline & Gender & 0.553 & 0.038 & \\
\hline & Education & -0.197 & 0.264 & \\
\hline & Income & -0.060 & 0.411 & \\
\hline & Chi-square: & 55,122 & & \\
\hline
\end{tabular}


To analyze to what extent gender differences along with other socio-economic characteristics can affect the importance given to the attributes of pizza, we developed the analysis of marginal effects. Since our dependent variable for each of the ordered regression model consists of seven categories, there are seven sets of marginal effects that describe the impact of a change in the covariates on the predicted probabilities. Technically, if the predicted probabilities obtained from the regressions reported in the previous Table 5 are varied across categories of the dependent variable, the marginal effects can be used to estimate their increase or decrease. Table 6 shows results of the marginal effects analysis.

Looking at marginal effects, "gender" affects the importance given to "smell" attribute, and overall females are less likely than males to give importance to "smell". The only exception is the marginal effects of the highest score obtained for this attribute (6) that takes a positive sign indicating a higher likelihood that females give importance to "smell" more than males. Conversely, the marginal effects of the other high importance scores (4 and 5) take a negative sign indicating a lower likelihood that females give importance to "smell" more than males. For example, the probability that a female gives a score of 4 or 5 to "smell" is respectively $5.0 \%$ and $6.2 \%$ lower than a man. For "education" attribute, higheducation level consumers are more likely to give a high score to "smell" attribute. In fact, the probability that consumers with high level of education gives a score of 4 or 5 to "smell" is respectively $3.5 \%$ and 4.3\% more than consumers with a low-education level. On the contrary, for the highest score of the attribute, the probability that consumers with high level of education give the score of 6 is $9.2 \%$ lower than consumers with a low level of education. Summarizing, the highest score for "smell" is given by females with a medium or low-level of income.

As for "appearance", the marginal effects show that males deem this attribute more important in buying of pizza than females except for the marginal effects of the highest score (7) that takes a positive sign indicating a higher likelihood that females give importance to "appearance" more than males. Highincome level negatively affects the probability to have high score for "appearance" since the probability that consumers with high income give a score of 7 is $2.9 \%$ lower than low-income level consumers. As detected for "smell", also for "appearance we observed that he highest score for this attribute is given by females with a medium or low-level of income.

A similar result was registered for "crunchiness". Females are more likely than males to give high importance to this attribute. In fact, the probability that a female gives a score of 7 to "crunchiness" is $12.0 \%$ higher than a man. On the contrary, education positively affects the probability to have high score for "crunchiness" with the exception for the highest score of 7. 
Finally, the probability that females give to "price" the highest score of 7 is $11.3 \%$ higher than males. For the other categories of "price", females are less likely than males to give importance to "price".

Table 6. Marginal effects for the ordered logit model

\begin{tabular}{|c|c|c|c|c|c|c|c|c|}
\hline & Variable & 1 & 2 & 3 & 4 & 5 & 6 & 7 \\
\hline \multirow{4}{*}{ Smell } & Age & $\begin{array}{c}-0.00008 \\
(0.423) \\
\end{array}$ & $\begin{array}{c}-0.00008 \\
(0.423) \\
\end{array}$ & $\begin{array}{c}-0.00037 \\
(0.249) \\
\end{array}$ & $\begin{array}{r}-0.00139 \\
(0.190) 1 \\
\end{array}$ & $\begin{array}{c}-0.00174 \\
(0.175) \\
\end{array}$ & $\begin{array}{c}0.00366 \\
(0.175) \\
\end{array}$ & \\
\hline & Gender & $\begin{array}{c}-0.00288 \\
(0.372)\end{array}$ & $\begin{array}{c}-0.00282 \\
(0.371)\end{array}$ & $\begin{array}{c}-0.01346 \\
(0.135)\end{array}$ & $\begin{array}{l}-0.05018 \\
(0.057 *)\end{array}$ & $\begin{array}{l}-0.06255 \\
(0.044 * *)\end{array}$ & $\begin{array}{c}0.13190 \\
(0.042 * *)\end{array}$ & \\
\hline & Education & $\begin{array}{c}0.00201 \\
(0.371)\end{array}$ & $\begin{array}{l}0.00197 \\
(0.370)\end{array}$ & $\begin{array}{c}0.00940 \\
(0.133)\end{array}$ & $\begin{array}{l}0.03507 \\
(0.056 *)\end{array}$ & $\begin{array}{c}0.04369 \\
(0.044 * *)\end{array}$ & $\begin{array}{l}-0.09214 \\
(0.041 * *)\end{array}$ & \\
\hline & Income & $\begin{array}{c}0.00045 \\
(0.450)\end{array}$ & $\begin{array}{l}0.00049 \\
(0.449)\end{array}$ & $\begin{array}{c}0.00213 \\
(0.302)\end{array}$ & $\begin{array}{c}0.00794 \\
(0.252)\end{array}$ & $\begin{array}{c}0.00990 \\
(0.249)\end{array}$ & $\begin{array}{c}-0.02087 \\
(0.244)\end{array}$ & \\
\hline \multirow{4}{*}{ Appearance } & Age & $\begin{array}{c}-0.00001 \\
(0.774)\end{array}$ & $\begin{array}{c}-0.00001 \\
(0.774)\end{array}$ & $\begin{array}{c}-0.00003 \\
(0.769)\end{array}$ & $\begin{array}{c}-0.00023 \\
(0.765)\end{array}$ & $\begin{array}{c}-0.00025 \\
(0.765)\end{array}$ & $\begin{array}{c}-0.00017 \\
(0.766)\end{array}$ & $\begin{array}{l}0.00070 \\
(0.764)\end{array}$ \\
\hline & Gender & $\begin{array}{c}-0.00263 \\
(0.371) \\
\end{array}$ & $\begin{array}{c}-0.00259 \\
(0.371) \\
\end{array}$ & $\begin{array}{c}-0.00507 \\
(0.246) \\
\end{array}$ & $\begin{array}{c}-0.03987 \\
(0.063 *) \\
\end{array}$ & $\begin{array}{r}-0.04345 \\
(0.051 *) \\
\end{array}$ & $\begin{array}{c}-0.02994 \\
(0.086 *) \\
\end{array}$ & $\begin{array}{c}0.12355 \\
(0.042 * *)\end{array}$ \\
\hline & Education & $\begin{array}{c}0.00063 \\
(0.562)\end{array}$ & $\begin{array}{l}0.00062 \\
(0.562)\end{array}$ & $\begin{array}{c}0.00121 \\
(0.524)\end{array}$ & $\begin{array}{c}0.00958 \\
(0.481)\end{array}$ & $\begin{array}{c}0.01045 \\
(0.478)\end{array}$ & $\begin{array}{c}0.00718 \\
(0.485)\end{array}$ & $\begin{array}{c}-0.02965 \\
(0.475)\end{array}$ \\
\hline & Income & $\begin{array}{c}0.00061 \\
(0.386)\end{array}$ & $\begin{array}{l}0.00060 \\
(0.386)\end{array}$ & $\begin{array}{c}0.00118 \\
(0.271)\end{array}$ & $\begin{array}{l}0.00930 \\
(0.099 *)\end{array}$ & $\begin{array}{l}0.01014 \\
(0.085 *)\end{array}$ & $\begin{array}{c}0.00698 \\
(0.135)\end{array}$ & $\begin{array}{l}-0.02883 \\
\left(0.080^{*}\right)\end{array}$ \\
\hline \multirow{4}{*}{ Crunchiness } & Age & $\begin{array}{c}-0.00008 \\
(0.828) \\
\end{array}$ & $\begin{array}{c}-0.00004 \\
(0.828) \\
\end{array}$ & $\begin{array}{c}-0.00009 \\
(0.827) \\
\end{array}$ & $\begin{array}{c}-0.00007 \\
(0.827) \\
\end{array}$ & $\begin{array}{c}-0.00015 \\
(0.827) \\
\end{array}$ & $\begin{array}{c}-0.00012 \\
(0.827) \\
\end{array}$ & $\begin{array}{l}0.00055 \\
(0.827) \\
\end{array}$ \\
\hline & Gender & $\begin{array}{c}-0.01711 \\
(0.121)\end{array}$ & $\begin{array}{c}-0.00903 \\
(0.165)\end{array}$ & $\begin{array}{c}-0.02058 \\
(0.098)\end{array}$ & $\begin{array}{c}-0.01628 \\
(0.101)\end{array}$ & $\begin{array}{c}-0.03223 \\
(0.070 *)\end{array}$ & $\begin{array}{l}-0.02516 \\
(0.087 *)\end{array}$ & $\begin{array}{c}0.12043 \\
\left(0.055^{*}\right)\end{array}$ \\
\hline & Education & $\begin{array}{c}0.01999 \\
(0.038 * *)\end{array}$ & $\begin{array}{r}0.01055 \\
\left(0.083^{*}\right) \\
\end{array}$ & $\begin{array}{c}0.02404 \\
(0.018 * *)\end{array}$ & $\begin{array}{c}0.01902 \\
(0.021 * *)\end{array}$ & $\begin{array}{c}0.03765 \\
(0.003 * * *)\end{array}$ & $\begin{array}{c}0.02944 \\
(0.012 * *)\end{array}$ & $\begin{array}{c}-0.14069 \\
(0.001 * * *)\end{array}$ \\
\hline & Income & $\begin{array}{c}-0.00003 \\
(0.991) \\
\end{array}$ & $\begin{array}{c}-0.00002 \\
(0.991) \\
\end{array}$ & $\begin{array}{c}-0.00003 \\
(0.991) \\
\end{array}$ & $\begin{array}{c}-0.00003 \\
(0.991) \\
\end{array}$ & $\begin{array}{c}-0.00005 \\
(0.991)\end{array}$ & $\begin{array}{c}-0.00004 \\
(0.991) \\
\end{array}$ & $\begin{array}{l}0.00020 \\
(0.991) \\
\end{array}$ \\
\hline \multirow{4}{*}{ Price } & Age & $\begin{array}{c}-0.00022 \\
(0.262) \\
\end{array}$ & $\begin{array}{c}-0.00029 \\
(0.235) \\
\end{array}$ & $\begin{array}{c}-0.00040 \\
(0.204) \\
\end{array}$ & $\begin{array}{c}-0.00141 \\
(0.149) \\
\end{array}$ & $\begin{array}{c}-0.00126 \\
(0.143) \\
\end{array}$ & $\begin{array}{c}0.00047 \\
(0.231) \\
\end{array}$ & $\begin{array}{l}0.00311 \\
(0.138) \\
\end{array}$ \\
\hline & Gender & $\begin{array}{c}-0.00814 \\
(0.181)\end{array}$ & $\begin{array}{c}-0.01038 \\
(0.146)\end{array}$ & $\begin{array}{c}-0.01456 \\
(0.106)\end{array}$ & $\begin{array}{c}-0.05103 \\
(0.044 * *)\end{array}$ & $\begin{array}{l}-0.04560 \\
(0.037 * *) \\
\end{array}$ & $\begin{array}{c}0.01691 \\
(0.144) \\
\end{array}$ & $\begin{array}{c}0.11280 \\
(0.034 * *) \\
\end{array}$ \\
\hline & Education & $\begin{array}{c}0.00290 \\
(0.346)\end{array}$ & $\begin{array}{l}0.00370 \\
(0.326)\end{array}$ & $\begin{array}{c}0.00519 \\
(0.306)\end{array}$ & $\begin{array}{c}0.01819 \\
(0.268) \\
\end{array}$ & $\begin{array}{c}0.01625 \\
(0.263)\end{array}$ & $\begin{array}{c}-0.00602 \\
(0.317)\end{array}$ & $\begin{array}{c}-0.04021 \\
(0.262)\end{array}$ \\
\hline & Income & $\begin{array}{c}0.00088 \\
(0.458) \\
\end{array}$ & $\begin{array}{l}0.00112 \\
(0.446)\end{array}$ & $\begin{array}{c}0.00158 \\
(0.434) \\
\end{array}$ & $\begin{array}{c}0.00555 \\
(0.413) \\
\end{array}$ & $\begin{array}{c}0.00497 \\
(0.411) \\
\end{array}$ & $\begin{array}{c}-0.00183 \\
(0.443) \\
\end{array}$ & $\begin{array}{c}-0.01227 \\
(0.410) \\
\end{array}$ \\
\hline
\end{tabular}

\section{Conclusion}

This paper sought to determine gender differences in consumption of one of the most traditional Italian foods: pizza. According to previous studies that pointed out a significant relationship between consumption of traditional local foods and gender differences (e.g. Rimal et al., 2005; Napolitano et al., 2010; Arganini et al., 2012; Gracia et al., 2012; Lassen et al., 2016), our findings referred to pizza showed that these relationships depend on different importance that females and males have about qualitative attributes of pizza such as "smell", "appearance", "crunchiness" and "price". Thus, the findings of this study revealed that differences in consumption of pizza can depend on gender preferences about qualitative attributes. 
Despite further researches are required to improve the sample representativeness and to provide a better understanding of marketing strategies suitable for capturing consumer preference for pizza, our results are quite significant, and main outcomes of this study can be reasonably generalized and considered consistent with the previous literature on food consumption by gender, whose methodological approach have been based on a limited number of observations (Ares and Gámbaro, 2007; de Magistris et al., 2014). The methodological approach used in this research could help in the identification of marketing strategies that could be addressed to specific action to promote consumption of the Italian traditional pizza. Moreover, our results could have important implications for restaurants, pizzerias and on overall for pizza industry (i.e. frozen pizza producers) and half-processed and/or packaged pizza producers since pizza is perceived as food for which some specific intrinsic characteristics can vary depending on consumers' gender.

For actors involved in pizza sector, the adoption of marketing practices explicitly related to the gender differences could increase consumers' valuation for pizza. Moreover, knowing factors affecting gender differences in pizza consumption can lead to an increase in pizza demand that could enhance firm income. This implies that in the formulation and characterization of pizza, it is necessary to consider the aspects related to gender differences that significantly influence the buying process. In addition, this research represents the first attempt at measuring gender preferences for pizza and can be considered as a methodological experiment easily replicable in other food sectors.

The authors are aware that the findings of this research should be interpreted with a certain caution, due to several factors that may be relevant when information regarding the adoption of business strategies by companies are provided such as small sample size interviewed, the quality of the information transmitted to respondents and other pizza's attributes not considered in this study. Moreover, since the participants in this study are from the city of Catania, the place-specific study findings cannot be generalized to all Italian consumers, and further analysis in other Italian areas are needed to improve external validity of our results.

\section{Acknowledgements}

A special thank goes to prof. Jayson Lusk for his support in the data analysis. 


\section{References}

Adalja, A., Hanson, J., Towe, C., \& Tselepidakis, E. (2013). An examination of consumer willingness to pay for local products. Agricultural and Applied Economics Association 2013 Annual Meeting, Washington, D.C.

Afifi-Soweid, R.A., Kteily, M.B.N., \& Shediac-Rizkallah, M.C. (2002). Preoccupation with weight and disordered eating behaviours of entering students at a university in Lebanon. International Journal of Eating Disorders, 32(1), 52-57. DOI: 10.1002/eat.10037

Akpinar, M. G., Aykin, S. M., Sayin, C., \& Ozkan, B. (2009). The role of demographic variables in purchasing decisions on fresh fruit and vegetables. Journal of Food, Agriculture and Environment, 7(3\&4), 106-110.

Allegra, V., Zarbà, A. S., \& Muratore, G. (2012). The post-purchase consumer behaviour, survey in the context of materials for food packaging. Italian Journal of Food Science, 24(4), 160-164.

Andreoni, J., \& Vesterlund, L. (2001). Which is the fair sex? Gender differences in altruism. Quarterly Journal of Economics, 116(1), pp. 293-312. doi.org/10.1162/003355301556419

Ares, G., \& Gámbaro, A. (2007). Influence of gender, age and motives underlying food choice on perceived healthiness and willingness to try functional foods. Appetite, 49(1), 148-158.

Arganini, C., Turrini, A., Saba, A., Virgili, F., \& Comitato, R. (2012). Gender differences in food choice and dietary intake in modern western societies. INTECH Open Access Publisher.

Barker, M.E., Thompson, K.A., \& McClean, S.I. (1995). Attitudinal dimensions of food choice and nutrient intake. British Journal of Nutrition, 74(5), 649-659. https://doi.org/10.1079/BJN19950168

Bazzani, C., Caputo, V., Nayga, R.M., \& Canavari, M. (2017). Revisiting Consumers' Valuation for Local Versus Organic Food Using a Non-Hypothetical Choice Experiment: Does Personality Matter? Food Quality And Preference, 62, 144-154. DOI: 10.1016/j.foodqual.2017.06.019

Courtenay, W.H. (2000). Behavioural factors associated with disease, injury, and death among men: evidence and implications for prevention. Journal of Men's Studies, 9(1), 81-142. http://dx.doi.org/10.3149/jms.0901.81

Cox, J. C. \& Deck C. A. (2006). When are women more generous than men? Economic Inquiry, 44(4), 587-598. DOI:10.1093/ei/cbj04

Crawford, D.A., \& Baghurst, K.I. (1990). Diet and health: a national survey of beliefs, behaviours and barriers to change in the community. Australian Journal of Nutrition and Dietetics, 47(4), 97-104.

Croson, R. \& Gneezy, U. (2009). Gender differences in preferences. Journal of Economic Literature, 47(2), 1-27. DOI: 10.1257/jel.47.2.448 
D'Amico, M., Di Vita, G., \& Monaco, L. (2016). Exploring environmental consciousness and consumer preferences for organic wines without sulfites. Journal of Cleaner Production, 120, 64-71. https://doi.org/10.1016/j.jclepro.2016.02.014

de Magistris, T., Gracia A. Albisu, LM (2014). Wine consumers preferences in Spain: an analysis using the best-worst scaling approach. Spanish Journal of Agricultural Research, (3), 529-541.

Dittmar, H., Beattie, J., \& Friese, S. (1995). Gender identity and material symbols: Objects and decision considerations in impulse purchases. Journal of Economic Psychology, 16(3), 491-511. http://dx.doi.org/10.1016/0167-4870(95)00023-H

Di Vita, G., Pappalardo, G., \& D’Amico M. (2016a). Exploring the determinants of consumption for an Italian traditional product: the case of pizza. Quality-Access to Success, 17(S1), 216-221.

Di Vita, G., De Salvo, G., Bracco, S., Gulisano, G. \& D’Amico, M. (2016b). Future market of pizza: which attributes do they matter. AGRIS on-line Papers in Economics and Informatics, 8(4), 59-71. DOI: $10.7160 / \mathrm{aol} .2016 .080406$

Di Vita, G., D’Amico M., Lombardi A., \& Pecorino B. (2016c). Evaluating low sodium content in food: the willingness to pay for salt-reduced bread, a case study. Agricultural Economics Review, 17(2), 8299.

Fagerli, R.A., \& Wandel, M. (1999). Gender Differences in Opinions and Practices with Regard to a “Healthy Diet". Appetite, 32(2), 171-190. DOI: 10.1006/appe.1998.0188

Friel, S., NicGabhainn, S., \& Kelleher, C. (1999). Main results of the national health and lifestyle surveys, SLAN and HBSC. Centre for Health Promotion Studies: National University of Ireland and Department of Health and Children, Galway.

Giampietri, E., Verneau, F., Del Giudice, T., Carfora, V., \& Finco, A. (2018). A Theory of Planned behaviour perspective for investigating the role of trust in consumer purchasing decision related to short food supply chains. Food Quality and Preference, 64, 160-166. http://dx.doi.org/10.1016/j.foodqual.2017.09.012

Gil, J. M., Gracia, A., \& Sanchez, M. (2000). Market segmentation and willingness to pay for organic products in Spain. The International Food and Agribusiness Management Review, 3(2), 207-226. https://doi.org/10.1016/S1096-7508(01)00040-4

Girgenti, V., Massaglia, S., Mosso, A., Peano, C., \& Brun, F. (2016). Exploring perceptions of raspberries and blueberries by Italian consumers. Sustainability, 8(10), 1027. https://doi.org/10.3390/su8101027 
Girois, S.B., Kumanykia, S.K., Morabia, A., \& Mauger, E. (2001). A comparison of knowledge and attitudes about diet and health among 35 to 75 year-old adults in the United States and Geneva, Switzerland. American Journal of Public Health, 91(3), 418-424. DOI: 10.2105/AJPH.91.3.418

Glanz, K., Basil, M., Maibach, E., Goldberg, J., \& Snyder, D. (1998). Why Americans eat what they do: taste, nutrition, cost, convenience, and weight control concerns as influences on food consumption. Journal of the American Dietetic Association, 98(10), 1118-1126. https://doi.org/10.1016/S00028223(98)00260-0

Goode, J., Beardsworth, A., Haslam, C., Keil, T., \& Sherratt, E. (1995). Dietary dilemmas: nutritional concerns of the 1990's. British Food Journal, 97(11), 3-12. https://doi.org/10.1108/00070709510105050

Gracia, A., De Magistris, T., \& Nayga, R. M. (2012). Importance of Social Influence in Consumers' Willingness to Pay for Local Food: Are There Gender Differences? Agribusiness, 28(3), 361-371. https://doi.org/10.1002/agr.21297

Gutman, J. (1982). A Means-End Chain Model Based on Consumer Categorization Processes. Journal of Marketing, 46, 60-72.

Johnson, F., \& Wardle, J. (2005). Dietary restraint, body dissatisfaction, and psychological distress: A prospective analysis. Journal of Abnormal Psychology, 114(1), 119-125.

Kiefer, I., Rathmanner, T., \& Kunze, M. (2005). Eating and dieting differences in men and women. The Journal of Men's Health \& Gender, 2(2), 194-201. DOI: 10.1037/0021-843X.114.1.119

Kostanski, M., Fisher, A., \& Gullone, E. (2004). Current conceptualization of body image dissatisfaction: Have we got to wrong? Journal of child Psychology and Psychiatry, 45(7), 1317-1325. DOI: 10.1111/j.1469-7610.2004.00315.x

Lanfranchi, M., Zirilli, A., Passantino, A., Alibrandi, A., \& Giannetto, C. (2017). Assessment of milk consumer preferences: Identifying the choice factors through the use of a discrete logistic model. British Food Journal, 119(12), 2753-2764. https://doi.org/10.1108/BFJ-04-2017-0210

Lanza, C.M., Mazzaglia, A., Scacco, A., \& Pecorino, B. (2011). Changes in sensory and instrumental features of industrial Sicilian bread during storage. Italian Journal of Food Science, 23(1), 6-12.

Lassen, A. D., Lehmann, C., Andersen, E. W., Werther, M. N., Thorsen, A. V., Trolle, E., ... \& Tetens, I. (2016). Gender differences in purchase intentions and reasons for meal selection among fast food customers-Opportunities for healthier and more sustainable fast food. Food Quality and Preference, 47, Part B, 123-129. DOI: 10.1016/j.foodqual.2015.06.011 
Lennernäs, M., Fjellström C., Becker, W., Giachetti, I., Schmitt, A., Remaut de Winter, A.M., \& Kearney. M. (1997). Influences on food choice perceived to be important by nationally-representative sample of adults in the European Union. European Journal of Clinical Nutrition, 51, suppl.2, 8-15.

Liebman, M., Cameron, B.A., Carson, D.K., Brown, D.M., \& Meyer, S.S. (2001). Dietary Fat Reduction Behaviours in College Students: Relationship to Dieting Status, Gender and Key Psychosocial Variables. Appetite, 36(1), 51-56. DOI: 10.1006/appe.2000.0383

Lusk, J., \& Briggeman, B.C. (2009). Food values. American Journal of Agricultural Economics, 91 (1), 184-196.

Lusk, J. (2011). External validity of the food values scale. Food Quality and Preference, 22, 452-462.

Margetts, B.M., Martinez, J.A., Saba, A., Holm, L., \& Kearney, M. (1997). Definitions of 'healthy' eating: a Pan-EU survey of consumers attitudes to food, nutrition and health. European Journal of Clinical Nutrition, 51, suppl.2, 23-29.

McCluskey, J. J., Grimsrud, K. M., Ouchi, H., \& Wahl, T. I. (2005). Bovine spongiform encephalopathy in japan: Consumers' food safety perceptions and willingness to pay for tested beef. Australian Journal of Agricultural and Resource Economics, 49 (2), 197-209.

Miles, S., Brennan, M., Kuznesof, S., Ness, M., Ritson, C., \& Frewer, L. J. (2004). Public worry about specific food safety issues. British Food Journal, 106(1), 9-22. https://doi.org/10.1108/00070700410515172

Missagia, S. V., de Oliveira, S. R., \& Carvalho de Rezende, D. (2012). Food Choice Motives and Healthy Eating: Assessing Gender differences. XXXVI Encontro da ANPAD, Rio de Janeiro, September $22-$ 26.

Napolitano, F., A. Braghieri, E. Piasentier, S. Favotto, S. Naspetti, \& Zanoli, R. (2010). Effect of information about organic production on beef liking and consumer willingness to pay. Food Quality and Preference, 21(2), 207-212. DOI: 10.1016/j.foodqual.2009.08.007

Olivas, R., \& Bernabéu, R. (2012). Men's and women's attitudes toward organic food consumption. A Spanish case study. Spanish Journal of Agricultural Research, 10(2), 281-291. http://dx.doi.org/10.5424/sjar/2012102-507-11

Pappalardo, G. \& Lusk J. (2016). The role of beliefs in purchasing process of functional foods. Food Quality and Preference, 53(2016), 151-158. http://dx.doi.org/10.1016/j.foodqual.2016.06.009

Parmenter, K., Waller, J. \& Wardle, J. (2000). Demographic variation in nutrition knowledge in England. Health Education Research, 15(2), 163-174. DOI: 10.1093/her/15.2.163 
Prattala, R., Paalanen, L., Grinberga, D., Helasoja, V., Kasmel, A., \& Petkeviciene, J. (2006). Gender differences in the consumption of meat, fruit and vegetables are similar in Finland and the Baltic countries. The European Journal of Public Health, 17(5), 520-525. DOI: 10.1093/eurpub/ck1265

Rappoport, L., Peters GR, Downey R, McCann T, \& Huff-Corzine L. (1993). Gender and age differences in food cognition. Appetite, 20(1), 33-52. DOI: 10.1006/appe.1993.1004

Rimal, P., Arbindra., Moon, W. \& Balasubramanian, S. (2005). Agro-biotechnology and organic food purchase in the United Kingdom. British Food Journal, 107(2), 84-97. https://doi.org/10.1108/00070700510579162

Rozin, P., Fischler, C., Imada, S., Sarubin, A., \& Wrzesniewski, A. (1999). Attitudes to food and the role of food in life in the U.S.A., Japan, Flemish Belgium and France: possible implication for the diethealth debate. Appetite, 33(2), 163-180. DOI: 10.1006/appe.1999.0244

Tate, J., \& Cade, J. (1990). Public knowledge of dietary fat and coronary heart disease. Health Education Journal, 49(1), 32-35. https://doi.org/10.1177/001789699004900112

Thiele, S, \& Weiss, C. R. (2003). Consumer Demand for Food Diversity: Evidence for Germany. Food Policy, 28 (2), 99-115. https://doi.org/10.1016/S0306-9192(02)00068-4

Wardle, J., Parmenter, K., \& Waller, J. (2000). Nutrition knowledge and food intake. Appetite, 34(3), 269-275. DOI: 10.1006/appe.1999.0311

Wardle, J., \& Griffith, J (2001). Socioeconomic status and weight control practices in British adults. Journal of Epidemiology \& Community Health, 55(3), 185-190. http://dx.doi.org/10.1136/jech.55.3.185 